\title{
THE PLACE OF MARKETING STRATEGIES IN THE CONSOLIDATION OF ROMANIAN BAKERY FIRMS
}

\author{
PhD Full, Professor Filimon Stremțan \\ PhD Candidate, Lecturer Andreea Muntean \\ “1Decembrie 1918” University Alba Iulia
}

\begin{abstract}
Stated by their marketing objectives, Romanian bakery firms have to opt for certain strategies for directing their activity in order to obtain desired target. In this field, marketing strategies refer to the way in which the organization approaches the market and the marketing mix. In the process of elaborating the marketing strategies, firms should follow to combine those with the general strategies of the organization.
\end{abstract}

Regarding their marketing objectives, Romanian bakery firms are advice to make their option for certain strategies that direct their activity towards gaining the desired position on the target market. In this domain, marketing strategies refers to the way in which industrial units are approaching the market and the elements of marketing mix.

A first issue that appears in this domain refers to the fact that when it comes to marketing strategies elaboration, firms must follow their harmonization with the general strategies of the industrial unit. For this purpose we have studied a series of methodological variants provided by different experts. Among these, we consider that the variant which is presented in the Table 1 can offer a solution for Romanian firms that we are dealing with.

Tabel 1. Strategy types within the industrial unit.

\begin{tabular}{|l|l|l|}
\hline $\begin{array}{l}\text { Strategy } \\
\text { components }\end{array}$ & Industrial unit's strategy & Marketing strategy \\
\hline 1. The purpose & $\begin{array}{l}\text { The domain in which the industrial } \\
\text { unit develops its activity. }\end{array}$ & $\begin{array}{l}\text { Segmentation of the market; } \\
\text { mark policy; product lines; } \\
\text { marketing programs. }\end{array}$ \\
\hline $\begin{array}{l}\text { 2. The } \\
\text { objectives }\end{array}$ & $\begin{array}{l}\text { Industrial unit's objectives: the rate of } \\
\text { turnover, profitability, investments } \\
\text { profitability, action profit etc. }\end{array}$ & $\begin{array}{l}\text { The objectives that concern } \\
\text { specific products on different } \\
\text { markets: market shares, sales, } \\
\text { consumer's satisfaction etc. }\end{array}$ \\
\hline $\begin{array}{l}\text { 3. Resources } \\
\text { assignment }\end{array}$ & $\begin{array}{l}\text { Resources assignment at firm level, } \\
\text { regarding the activity portfolio, and } \\
\text { the research-development programme. }\end{array}$ & $\begin{array}{l}\text { Resources assignment } \\
\text { necessary for marketing mix, } \\
\text { conformable to marketing } \\
\text { programs. }\end{array}$ \\
\hline $\begin{array}{l}\text { 4. Competitive } \\
\text { advantages } \\
\text { sources }\end{array}$ & $\begin{array}{l}\text { Using the financial or human } \\
\text { resources of the industrial unit at a } \\
\text { superior level; research-development } \\
\text { programs and improving synergetic } \\
\text { and organizational processes for all } \\
\text { activity domains of the firm compared } \\
\text { to competition. }\end{array}$ & $\begin{array}{l}\text { Through an efficient product } \\
\text { positioning, through } \\
\text { superiority of the marketing } \\
\text { mix elements compared to } \\
\text { competition in a specific } \\
\text { market. }\end{array}$ \\
\hline $\begin{array}{l}\text { 5. Synergy } \\
\text { sources }\end{array}$ & $\begin{array}{l}\text { Resources, technology and financial } \\
\text { competences of the industrial unit } \\
\text { assignation in the progress of the } \\
\text { business. }\end{array}$ & $\begin{array}{l}\text { Marketing resources, } \\
\text { competences or activities } \\
\text { assignation when entering on } \\
\text { a specific market. }\end{array}$ \\
\hline
\end{tabular}


Synthesizing the content of the table and taking into consideration the particularities of the bakery domain, we can group the strategies in two large categories:

- $\quad$ superior level strategies, which propose themselves to fulfill the industrial unit's mission;

- $\quad$ competitive strategies that assure and support the competitive advantage of the industrial unit.

Also, we have to mention, that marketing strategies from this domain will have to be adapted to the stage in which the product is within its life cycle and within the competitive position of the firm.

Another important problem concerning the wording and grounding of firm strategies regarding the orientation and development of production, distribution and even the consumption of bakery products on Romanian market refers to observing the action frame coordinates of the respective units. The dimensions of this frame must observe market's exactingnesses for every product, the specific objectives of every firm: the life cycle of either firm or product, when the strategy actions are initiated. Taking into consideration those frame aspects as well as methodological reasons provided by special literature, we consider that, on the basis of H. Igor Ansoff concepts, the industrial unit can resort to the elaboration of many marketing strategies, appealing to product-market matrix which offers a generous set of possible variables.

Market penetration strategy. The industrial unit's decision to develop on certain markets, through actual products, materializes in a penetration strategy. Penetration strategies depend on two major factors: market's evolution phase and the rival's position on the target market. Through these strategies, on developing markets, the firms which hold small market shares or firms that are new on the market can obtain a larger weight on that market. This growing is possible when the other market operators can not or are not interested in satisfying the growing demand, although they register a growth of their own sales. On mature markets the penetration strategy is more difficult because the market's leaders have the low-costs advantage, which restricts the attempts of increasing the market shares of newcomers.

A declining market gives the possibility to penetrate when it comes to holding it by certain firms. Increasing sales on this market, followed through penetration strategies, can be achieved in the following modalities: attracting relative non consumers of the product; increasing client's fidelity towards the offered products; encouraging product's consumption. Those strategies are recommended especially to bakery firms, which, on the Romanian market, follow launching some products that are for a certain category of consumers. For example: pizza for young people, pretzels, and pastry products.

Consolidation strategy. Holding the position on actual markets sometimes requires making some changes in the way in which industrial unit operates. Consolidation strategies must be adapted to actual market situation. In the case of developing markets, the consolidation of the position in report to competitors imposes the increase of industrial unit's market shares in a development rate equal to that of the market. Mature markets require different approaches, meaning strategies that stress on product quality, costs cutting and amplification of marketing activities. On Romanian market, this kind of strategy is recommended to large firms, with modern theological endows, that can offer a scale of pastry products that are wrapped and distributed in safe alimentary conditions, and with a high degree of keeping up the quality and freshness, such as: wrapped assortments of bread, sliced an with seeds, wrapped pastry products, delivery at home of certain bakery products etc.

Market development strategy. This strategy refers to localization of some geographical areas in which the firm's products are not present or even to some segments from the actual market area. On these terms, for certain clients, the launched product may be completely new or may compete along with other similar product available on the market. 
The set of strategies comprised in "market development strategies" is recommended to small and medium firms that are trying to extend their market especially through this kind of methods.

According to products development strategy, the firms are trying to formulate a product development strategy for existing markets capitalizing their experience and competence in a favorable extern environment. This products development strategy can lead to sales growth within the same category of consumers. The success of this strategy can be done with the help of some research-development departments that develop a strategy according to the needs of potential consumers for a segment of target market. Also, the success of this strategy can base itself on launching a new product on the account of reduction the sales to other existing products in the fabrication range of the firm.

Within the Romanian bakery products market those strategies are recommended to all small, medium and large firms, which stress on developing the research-development activities, on studies and marketing analyses.

Diversification strategy. This strategy is orientated towards the diversification of production through making and launching new products, either on connected domains or in domains that are different of those that the firm is involved. Within this strategy, the firm can resort to three diversification variants.

- $\quad$ forward integration, that consists of industrial unit's implication in assuring the necessary inputs to its activity. For example, Loulis firm adopts the acquisition strategy of some mills that assure the flour outfit.

- $\quad$ backward integration, that refers to the activities diversification connected to the outputs of the firm. In this case, the firms can extend their own channels of distribution, including service performance connected to the offered products.

- $\quad$ horizontal integration, that requires the development of the activity in which the firm is operating now. For example, the firms that produce bread will diversify the production through organizing a pastry activity.

The operation for diversification in connected or different domains is determined by the synergy that could be made in this way. The synergy in connected diversification is owed to products or markets. The diversification in distinct domains is based on financial synergy or managerial experience. We believe that within the Romanian market there was this kind of preoccupations along the firms with powerful financial potential, with tradition in making and selling bakery products.

The withdrawal strategy. In marketing plans, this variant is seen quite rarely. However, there are numerous situations when full or partial withdrawal from the markets is a recommendable strategy. Adopting this kind of strategy, leads to selling the products, the actives or the entire business to other market operators.

In wording and grounding the firm strategies, within the trading companies which act for making and distributing the bakery product, an important aspect consists of shaping the relations between the basic industrial unit's strategies - considered generic - and the marketing ones. For this it is considered that wording the marketing strategies starts from generic strategy for which the industrial unit made its option according to its objectives. As Michael E. Porter thinks, the industrial unit can choose one from a series of generic strategies variants typical for the functional market economies.

- The lower totally cost strategy, a type of strategy that capitalizes all the advantage sources referring to production and distribution costs.

- Differentiation strategy through which the industrial unit can create a unique position offering certain advantages that are appreciated by buyers (for 
example, the industrial unit offers the quality of products and services at a higher price).

- Focusing strategy. In this case, the industrial unit's strategy focuses only on certain market segments giving up covering the entire market.

Another important domain of defining the coordinates of the firm strategies, within the bakery sector, consists of establishing the ways of administration and orientation of the relations within the marketing mix that is specific to this sector. In the same time it is necessary to point out the fact that for establishing the strategy specific to the functional area of marketing, the " $4 \mathrm{P}$ " (product, price, promotion, distribution), are made up real reference elements in all activity area of a bakery firm. This happens because representing the essence of a marketing firm activity or strategic business units orientated intensely towards the market, the marketing mix comprises the main elements that give the strategic preoccupations of the unit, such as: offered product/service, price or the scale of prices, promoting sales and distribution, meaning the entire direct trade, retail sellers, the transport and stocking system. Otherwise, strategic marketing planning comprises, as J.H.Myers sees it, the successive sequences of identification the opportunities, the selection of markets that are interesting for the firm, positioning the product, establishing qualitative objectives, developing the marketing mix.

The market segmentation strategy consists of selling the standardized product on a relevant segment of the total market, relevant market meaning the segment from the total possible market of a product, which the firm limited in order to serve and which other competitive firms are dealing with.

Concerning the segmentation strategy is necessary to take into consideration that within the bakery domain, market segmentation can be made according to numerous factors, grouped depending on individuals and houses characteristics, on functional product characteristics and on marketing mix characteristics:

- Characteristics concerning the individuals and the houses: they take into consideration demographic aspects - age, sex, incomes, degree of instruction, and the medium dimensions of a family; geographic - central or peripherical areas of the cities, rural or urban environment, specific regions or provinces; life styles - needs, interests, aspirations, personal values etc.

- Functional characteristics of the product refers to quality, manageability, reliability, using frequency, using way (individual or combined with other products), using terms (current or at special occasions).

- The characteristics of marketing mix comprise: the characteristics asked by product's buyers, prices range, promoting the ways of selling, distribution organization.

Commodity strategy deals with selling a standardized product possibility on the entire relevant market, characterized by orientation towards the production and not towards the market or the product, high volume of sales, reduced product price, minimal marketing efforts.

Specialization strategy, somehow more exacting and demanding higher efforts, consists of individualization the product and narrowing the market that the product is commercialized, in this way, representing a synthesis of the two specific strategies having these objectives. This kind of strategy is recommended to bakery firms that make products such as: pastes, biscuits and sugary products.

Differentiation strategy of the product follows the realization, in buyers own perception, that the offered products are unique, and may refer to large or narrow segments of the market. Differentiation strategy is for all the segments of the activity chain - firm specific costs, each of the component segments having its specific contribution (supplying with raw materials, research-development activities, production processes, marketing activities, sales 
and post-sales). On Romanian market this strategy is recommended to all the bakery firms, no matter what size they are.

Establishing and applying the firm's strategy is the main responsibility of is managers, the quality of the adopted and followed strategy accurate reflecting the managerial capacity to preview, with professionalism, realism and daring, the place where the firm's evolution will be recorded further on. Identifying the best strategy to follow by the firm is a complex approach, in which one must take into account the firm's condition as a whole - the strong issues and the weaknesses that the firm has, its capabilities, its competitive advantages and distinctive held competences - as well as the actual condition and its action environment perspective, on the impact that the approach will have over the firm.

\section{Bibliography:}

1. Balaure V. şi colab., „Marketing”, Editura Uranus, Bucureşti, 2000

2. Berman B.,"Marketing Channels", Edition John Willey \& Sons Inc., New York, 2000

3. Bigioi D. „An analysis of the bakery sector in Ireland”, M.Econ. Science, National University of Ireland, Galway, Ireland, 2001

4. Kotler, Ph, Managementul marketingului, Editura Teora, Bucure;ti, 1998 
